09,12

\title{
Проявление квантоворазмерных эффектов в нанокристаллах и аморфных нанокластерах германия в пленках GeSixOy
}

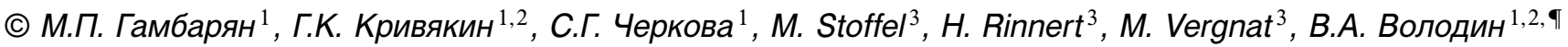 \\ ${ }^{1}$ Институт фризики полупроводников им. А.В. Ржанова СО РАН, \\ Новосибирск, Россия \\ ${ }^{2}$ Новосибирский государственный университет, \\ Новосибирск, Россия \\ ${ }^{3}$ Université de Lorraine, Institut Jean Lamour UMR CNRS 7198 B.P. 70239 , \\ 54506 Vandoeuvre-lés-Nancy, Cedex, France \\ ฯ E-mail: volodin@isp.nsc.ru
}

Поступила в Редакцию 25 сентября 2019 г.

В окончательной редакции 23 октября 2019 г.

Принята к публикации 23 октября 2019 г.

\begin{abstract}
Пленки нестехиометрических германосиликатных стекол двух типов $\mathrm{GeO}_{x}[\mathrm{SiO}]_{(1-x)}$ и $\mathrm{GeO}_{x}\left[\mathrm{SiO}_{2}\right]_{(1-x)}$ были получены высоковакуумным испарением порошков $\mathrm{GeO}_{2}$ и $\mathrm{SiO}$ либо $\mathrm{SiO}_{2}$, и напылением на холодную подложку $\mathrm{Si}(001)$. Исходные и подвергнутые отжигам $\left(550\right.$ и $\left.650^{\circ} \mathrm{C}, 1 \mathrm{~h}\right)$ образцы исследовали методами ИК-спектрокопии, электронной микроскопии, спектроскопии комбинационного рассеяния света (КРС) и фотолю2минесценции (ФЛ). Из анализа спектров КРС установлено, что в отличие от исходной пленки $\mathrm{GeO}\left[\mathrm{SiO}_{2}\right]$, пленка $\mathrm{GeO}[\mathrm{SiO}]$ изначально содержала кластеры аморфного германия. По данным электронной микроскопии размер кластеров составлял $\sim 3 \mathrm{~nm}$. ИК-спектроскопия показала наличие в пленках связей $\mathrm{Si}-\mathrm{O}, \mathrm{Ge}-\mathrm{O}$ и $\mathrm{Si}-\mathrm{O}-\mathrm{Ge}$. После отжига $550^{\circ} \mathrm{C}$ в обеих пленках были обнаружены кластеры аморфного германия, а после отжига $650^{\circ} \mathrm{C}$ в них появляются нанокристаллы германия. В исходных пленках при низких температурах наблюдалась широкая полоса ФЛ с максимумом $1050 \mathrm{~nm}$, вероятно, обусловленная дефектами - вакансиями кислорода и избыточными атомами германия. Отжиги вызывают трансформацию структуры пленок и меняют вид спектров ФЛ. В пленках, содержащих нанокластеры германия, наблюдается ФЛ с максимумом 1400-1600 nm. При этом уменьшился сигнал ФЛ от дефектов. Исследована температурная зависимость интенсивности пиков ФЛ, она падала с ростом температуры, но сохранялась при температурах до $200 \mathrm{~K}$. Обсуждается вклад в ФЛ от нанокристаллов германия, формируемых при отжигах.
\end{abstract}

Ключевые слова: германосиликатные стекла, нанокластеры германия, фотолюминесценция, квантоворазмерный эффект.

DOI: 10.21883/FTT.2020.03.49010.600

\section{1. Введение}

Нанокристаллы и аморфные нанокластеры кремния и германия в диэлектрических пленках представляют собой квантовые точки, и интересны с фундаментальной точки зрения, а также перспективны для нано- и оптоэлектроники $[1,2]$. Их свойствами можно управлять, используя квантово-размерные эффекты. Применение оптических линий связи (вместо электрических проводников) для передачи данных внутри чипа приведет к росту быстродействия микропроцессоров. В 2015 г. был создан микропроцессор, с полностью оптической связью [3], однако инфракрасное (ИК) излучение вводилось в него от внешнего источника.

Вследствие своей непрямозонной структуры объемный германий $(\mathrm{Ge})$ не может излучать свет с высокой эффективностью. Исследователи пытаются использовать ряд подходов для преодоления этого фундаментального ограничения, такие как смягчение правил отбора по квазиимпульсу в квантоворазмерных нанокластерах [47]; приложение деформаций, изменяющих зонную струк- туру [8-10]; создание светоизлучающих дефектов [1113]; создание наночастиц $\mathrm{Ge}_{x} \mathrm{Si}_{1-x}$ [14-20]. В то время как нанокристаллы (НК) кремния хорошо изучены, НК $\mathrm{Ge}$ изучались не столь интенсивно, хотя они обладают преимуществами. Например, температура кристаллизации германия ниже, чем у кремния, что позволяет снизить термический бюджет процессов [19-22].

Недавно в пленках германосиликатного нестехиометрического стекла $\mathrm{GeSixO}_{y}$ была обнаружена фотолюминесценция в ИК-диапазоне, предположительно обусловленная дефектами [13]. В настоящей работе для получения светоизлучающих дефектов и нанокластеров $\mathrm{Ge}$ мы использовали печные отжиги пленок $\mathrm{GeO}_{x}[\mathrm{SiO}]_{(1-x)}$ и $\mathrm{GeO}_{x}\left[\mathrm{SiO}_{2}\right]_{(1-x)}$, полученные сораспылением соответствующих мишеней в высоком вакууме и осаждением на подложки, находящиеся при температуре $100^{\circ} \mathrm{C}$.

\section{2. Описание эксперимента}

Пленки нестехиометрических германосиликатных стекол двух типов $\mathrm{GeO}_{x}[\mathrm{SiO}]_{(1-x)}$ и $\mathrm{GeO}_{x}\left[\mathrm{SiO}_{2}\right]_{(1-x)}$ 
были получены путем совместного испарения электронными пучками мишеней $\mathrm{GeO}_{2}$ и $\mathrm{SiO}$ (либо $\mathrm{GeO}_{2}$ и $\left.\mathrm{SiO}_{2}\right)$ в высоком вакууме $\left(10^{-8}\right.$ Torr $)$ и осаждения на подложках $\mathrm{Si}(001)$, находящихся при температуре $100^{\circ} \mathrm{C}$. Скорость осаждения каждого материала контролировалась с применением датчика кварцевого микробаланса, молярная доля компонентов (стехиометрический параметр $x$ ) зависела от отношения скоростей осаждения материалов. Известно, что при испарении мишени $\mathrm{GeO}_{2}$ на подложку осаждается слой $\mathrm{GeO}_{y}$, со стехиометрическим параметром $y$ равном примерно 1-1.1 [21-24]. По-видимому, это связано с большой летучестью монооксида германия и его не такой высокой (как у субоксидов кремния) химической активностью (скорость химической реакции его окисления до диоксида в присутствии дополнительного кислорода не так высока, как у монооксида кремния). Толщина пленок составляла $\sim 400 \mathrm{~nm}$, они покрывались защитным слоем $\mathrm{SiO}_{2}$ толщиной $10 \mathrm{~nm}$. Были осаждены слои с параметром $x \sim 0.5$. Затем образцы отжигали в атмосфере аргона при температурах 550 и $650^{\circ} \mathrm{C}$, время отжига составляло $1 \mathrm{~h}$.

Спектроскопия комбинационного рассеяния света (КРС) использовалась для анализа структуры образцов. Спектры КРС регистрировались в геометрии обратного рассеяния, источником возбуждения являлась линия $\mathrm{Ar}^{+}$лазера с длиной волны $514.5 \mathrm{~nm}$. Использовался спектрометр T64000 (Horiba Jobin Yvon) в одинарной моде, спектральное разрешение было не хуже $2 \mathrm{~cm}^{-1}$. Образцы также были исследованы с помощью инфракрасной фурье-спектроскопии поглощения (FTIR), применялся спектрометр ФТ-801 (производство ООО НПФ „СИМЕКС“, Новосибирск) со спектральным разрешением $4 \mathrm{~cm}^{-1}$. Оптические свойства отожженных образцов были исследованы с помощью спектроскопии фотолюминесценции (ФЛ). Не-Cd-лазер (длина волны излучения $325 \mathrm{~nm}$ ) использовался для возбуждения ФЛ. Для исследования низкотемпературной ФЛ применялся гелиевый криостат с точностью установки температуры \pm 1 К. Спектры ФЛ в ИК диапазоне измеряли с помощью монохроматора, снабженного решеткой $600 \mathrm{lines} / \mathrm{mm}$, и охлаждаемым жидким азотом InGaAs-диодом в качестве детектора. Спектры ФЛ не были скорректированы с учетом спектральной чувствительности детектора, длинноволновый край порога чувствительности составлял $1600 \mathrm{~nm}$. Для исследования ФЛ в видимом диапазоне при комнатной температуре в качестве детектора использовался фотоэлектрический умножитель.

Структурные свойства образцов были исследованы с помощью электронного микроскопа (JEM-2200FS, ускоряющее напряжение $200 \mathrm{kV}$ ) в режиме просвечивающей высокоразрешающей электронной микроскопии (ПВРЭМ, High resolution transmittance electron microscopy - HRTEM). Образцы для исследования ПВРЭМ в поперечном сечении (cross-section) получали механической полировкой с использованием микроскопа
Leica EM TXP с последующим утонением ионным пучком.

\section{3. Результаты и обсуждение}

Так как мощность испарителей была выбрана так, чтобы скорость осаждения компонент была одинаковой, стехиометрический параметр х пленок составлял $\sim 0.5$. В дальнейшем мы будем обозначать их как $\mathrm{GeO}[\mathrm{SiO}]$ и $\mathrm{GeO}\left[\mathrm{SiO}_{2}\right]$.

На рис. $1 a, b$ приведена эволюция спектров КРС образцов в процессе отжигов. Все спектры были измерены при комнатной температуре. Чтобы избежать нагрева пленки, лазерный луч был слегка расфокусирован, диаметр пятна составлял $10 \mu \mathrm{m}$, мощность излучения на поверхности составляла $\sim 1 \mathrm{mV}$. Поскольку исходные пленки были полупрозрачны, то в их спектрах проявлялись особенности, связанные с КРС от подложки монокристаллического кремния. Известно, что двухфононное рассеяние на монокристаллическом кремнии имеет ряд особенностей. Это широкий пик с максимумом $305 \mathrm{~cm}^{-1}$, обусловленный рассеянием на двух поперечных акустических фононах (2-ТА пик) [25], который проявляется в виде очень слабой особенности в спектре 1 на рис. $1, a$. Других особенностей в спектре исходной пленки $\mathrm{GeO}\left[\mathrm{SiO}_{2}\right]$ нет, значит в ней отсутствуют связи $\mathrm{Ge}-\mathrm{Ge}$. В спектре исходного образца $\mathrm{GeO}[\mathrm{SiO}]$ (кривая 1 на рис. $1, b)$ присутствует широкий пик (с максимумом $\sim 275 \mathrm{~cm}^{-1}$ ), связанный с рассеянием на оптических колебаниях в аморфном германии [27]. Значит, даже при относительно низкой температуре осаждения, происходит реакция

$$
\mathrm{GeO}+\mathrm{SiO}=\mathrm{Ge}+\mathrm{SiO}_{2}
$$

Это наблюдалось нами ранее [27]. Как показали отжиги, не весь монооксид германия прореагировал с образованием кластеров германия.

Видно, что отжиги при температуре $550^{\circ} \mathrm{C}$ приводят к росту сигнала от аморфного германия для пленки $\mathrm{GeO}[\mathrm{SiO}]$ (кривая 2 на рис. $1, b)$ и к возникновению данного пика для пленки $\mathrm{GeO}\left[\mathrm{SiO}_{2}\right]$ (кривая 2 на рис. $1, a$ ). Проявляется также слабая особенность $\left(180 \mathrm{~cm}^{-1}\right)$, связанная с рассеянием на оптических колебаниях связей $\mathrm{Ge}-\mathrm{Ge}$ продольного типа. Очевидно, отжиги способствуют собиранию германия в кластеры, растет их количество и размеры. После отжига при температуре $650^{\circ} \mathrm{C}$ в спектрах возник узкий пик (с положением $\sim 300 \mathrm{~cm}^{-1}$ ), характерный для кристаллического германия [28]. Сдвиг его положения в сравнении с пиком от монокристаллического германия (кривая 4 на рис. $1 a, b$ ), говорит о том, что оптические фононы локализованы в $\mathrm{HK}$ Ge. Итак, при температуре $650^{\circ} \mathrm{C}$ в обеих пленках формируются НК $\mathrm{Ge}$, причем в пленке $\mathrm{GeO}[\mathrm{SiO}]$ (кривая 3 на рис. $1, b)$ доля аморфной фазы германия заметно больше чем в пленке $\mathrm{GeO}\left[\mathrm{SiO}_{2}\right]$ (кривая 3 на рис. $1, a$ ). Экспериментальные спектры КРС были разложены на 

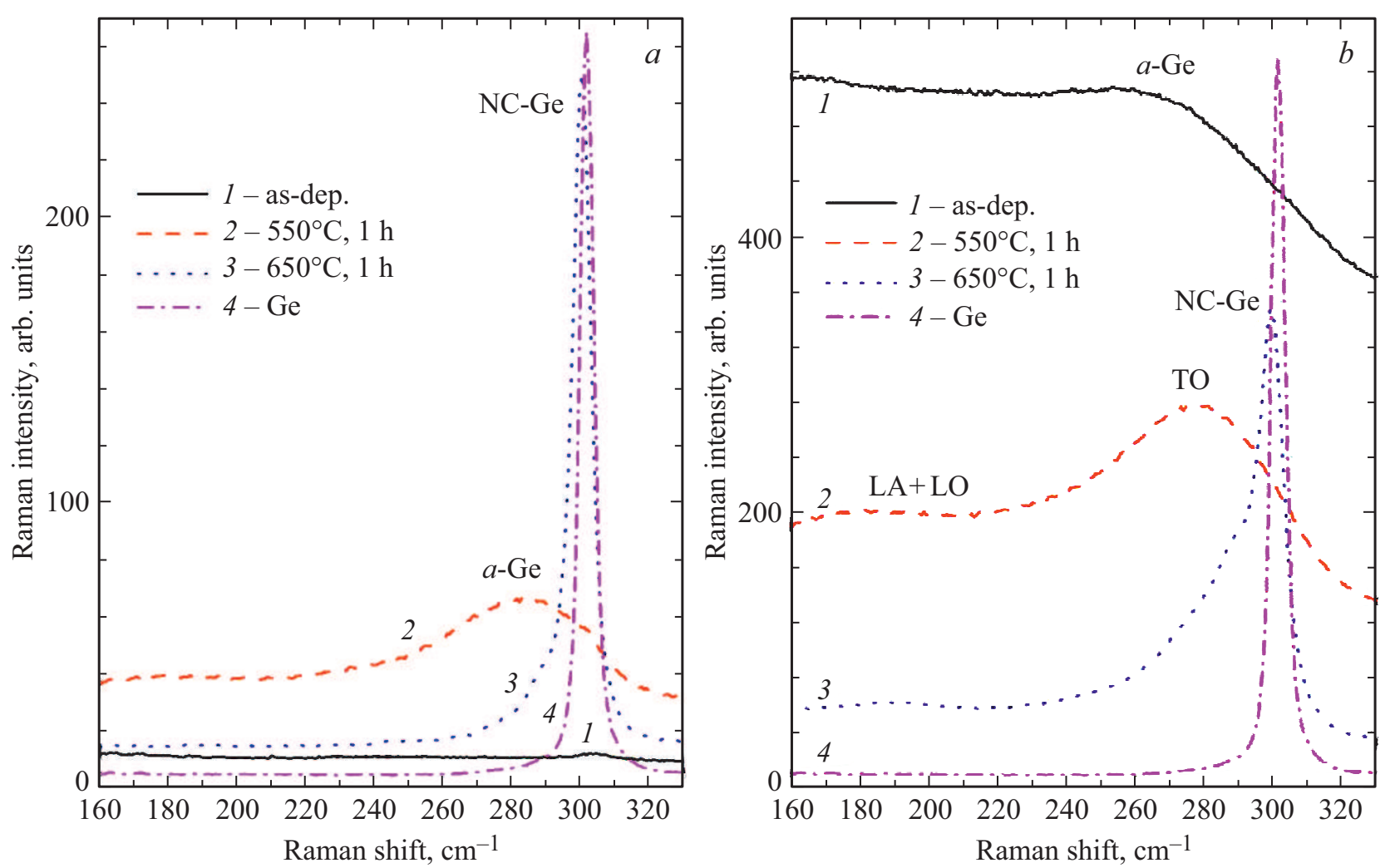

Рис. 1. Спектры комбинационного рассеяния света исходных образцов и после отжигов 550 и $650^{\circ} \mathrm{C}: a-\mathrm{GeO}^{2}\left[\mathrm{SiO}_{2}\right]$; $b-\mathrm{GeO}[\mathrm{SiO}]$.

составляющие пики (контуры Фойгта). При разложении спектров КРС на пики мы определяли положение пиков. Известно, что частота локализованных в $\mathrm{HK}$ Ge оптических фононов уменьшается с уменьшением их размеров [29]. В нашем случае, согласно модели локализации фононов [29], размер НК германия составляет $\sim 6.5 \mathrm{~nm}$ для пленки $\mathrm{GeO}\left[\mathrm{SiO}_{2}\right]$ и $\sim 6 \mathrm{~nm}$ для пленки $\mathrm{GeO}[\mathrm{SiO}]$. Это небольшое различие связано с тем, что в нашем случае НК Ge предположительно окружены не матрицей окисла, а переходным аморфным слоем германия, и толщина этого слоя больше в случае пленки $\mathrm{GeO}[\mathrm{SiO}]$. Как будет показано далее, это хорошо соответствует данным, полученным электронной микроскопией.

На рис. 2, $a, b$ показаны спектры ИК-поглощения образцов в области частот колебаний $\mathrm{Ge}-\mathrm{O}$ и $\mathrm{Si}-\mathrm{O}-$-вязей, а также в области частот колебаний O-Н-связей. Известно, что валентные колебания связей $\mathrm{O}-\mathrm{H}$ дают поглощение в районе $3300-3500 \mathrm{~cm}^{-1}$. Этот пик в поглощении от воды наблюдался для исходных образцов. По-видимому, вода содержалась в порах пленок. Видно, что после отжигов данный пик исчезал, отжиги приводили к удалению воды из пор, и, вероятно к исчезновению самих пор, к уплотнению пленок. В качестве эталонного образца при записи спектров ИК-поглощения использовалась подложка кремния без пленок. Так как в некотором спектральном диапазоне пленка являлась просветляющим покрытием, то абсо- лютное значение поглощения в этом диапазоне могло принимать отрицательные значения.

На рис. 2, $a, b$ видно, что отжиги привели к трансформации спектра поглощения в области частот колебаний $\mathrm{Ge}-\mathrm{O}$ и $\mathrm{Si}-\mathrm{O}-$-вязей. Наиболее интенсивный пик поглощения на антисимметричных валентных колебаниях (так называемая $\mathrm{TO}_{3}$ мода [30]) сдвинулся с $1070 \mathrm{~cm}^{-1}$ в исходной пленке $\mathrm{GeO}\left[\mathrm{SiO}_{2}\right]$ до $1075 \mathrm{~cm}^{-1}$ в отожженных (рис. $2, a$ ). В пленке $\mathrm{GeO}[\mathrm{SiO}]$ данный пик сдвинулся еще больше - от $1035 \mathrm{~cm}^{-1}$ в исходной пленке до $1070 \mathrm{~cm}^{-1}$ после отжига $550^{\circ} \mathrm{C}$, и до $1075 \mathrm{~cm}^{-1}$ после отжига $650^{\circ} \mathrm{C}$ (рис. 2,b). Пай с соавторами [31] установили, что положение данного пика (в обратных сантиметрах) в пленках $\mathrm{SiO}_{x}$ практически линейно зависит от стехиометрического параметра $x$, как

$$
v\left(\mathrm{TO}_{3}, \mathrm{SiO}_{x}\right)=925+75 x .
$$

В нашем случае, как и в случае отжига структур $\mathrm{Ge}_{x}\left[\mathrm{SiO}_{2}\right]_{(1-x)}[32]$, сдвиг, по-видимому, обусловлен, отжигом дефектов (пор и вакансий).

Видимый в пленке $\mathrm{GeO}\left[\mathrm{SiO}_{2}\right]$ пик с положением $\sim 990 \mathrm{~cm}^{-1}$ (кривая 1, рис. 2, a) обусловлен поглощением на колебаниях $\mathrm{Ge}-\mathrm{O}-\mathrm{Si}$ в германосиликатном стекле $[13,32,33]$. Помимо пиков $\mathrm{Si}-\mathrm{O}$ и $\mathrm{Si}-\mathrm{O}-\mathrm{Ge}$ в пленках видны пики, связанные с валентными колебаниями $\mathrm{Ge}-\mathrm{O}$ связей $[34,35]$. Подобно нестехиометрическому оксиду кремния, положение данного пика (в обратных 

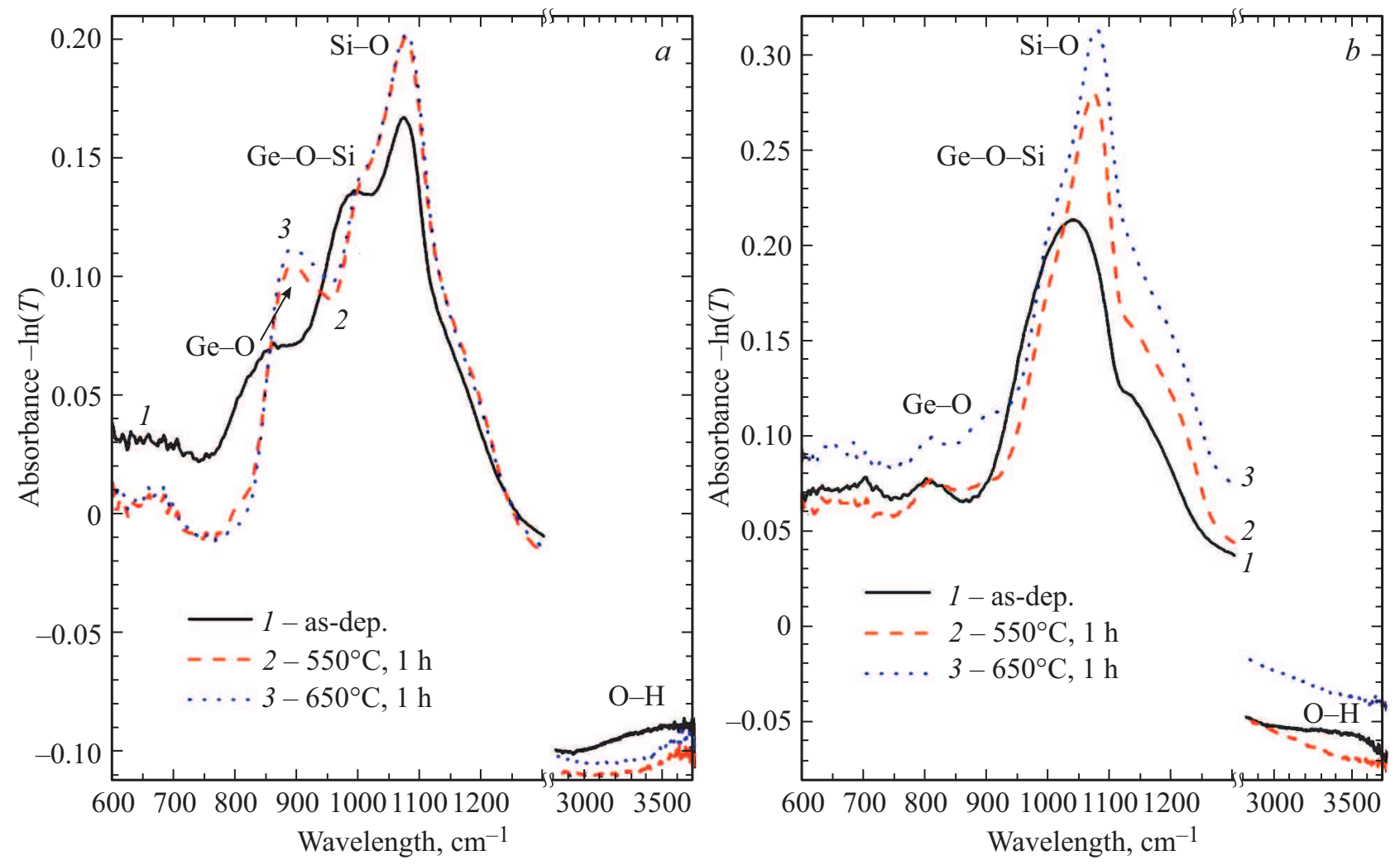

Рис. 2. Спектры ИК-поглощения исходных образцов и после отжигов 550 и $650{ }^{\circ} \mathrm{C}: a-\mathrm{GeO}\left[\mathrm{SiO}_{2}\right] ; b-\mathrm{GeO}[\mathrm{SiO}]$.

сантиметрах) в пленках $\mathrm{GeO}_{x}$ практически линейно зависит от стехиометрического параметра $x$ [35], как

$$
v\left(\mathrm{TO}_{3}, \mathrm{GeO}_{x}\right)=743+72.4 x \text {. }
$$

Таким образом, особенно в пленке $\mathrm{GeO}\left[\mathrm{SiO}_{2}\right]$ (рис. 2,a) видно, что отжиги привели к деконволюции монооксида германия на германий и диоксид германия по реакции $[7,22]$ :

$$
2 \mathrm{GeO}=\mathrm{Ge}+\mathrm{GeO}_{2} .
$$

Как уже отмечалось, данные ПВРЭМ (рис. $3 a-d$ ) подтвердили результаты, полученные из анализа данных спектроскопии КРС. В исходной пленке $\mathrm{GeO}[\mathrm{SiO}]$ были обнаружены нанокластеры аморфного германия с размерами около $3 \mathrm{~nm}$ (рис. 3,a). Отжиг при температуре $650^{\circ} \mathrm{C}$ привел к их кристаллизации и росту размеров (рис. $3, b$ ), видны плоскости из атомов германия, средний размер нанокристаллов составляет 5-6 nm. Интересно, что отжиг при температуре $650^{\circ} \mathrm{C}$ пленки $\mathrm{GeO}\left[\mathrm{SiO}_{2}\right]$ привел к возникновению слоистой структуры из довольно больших (и иногда ограненных) агломератов из $\mathrm{HK} \mathrm{Ge}$ (рис. 3,c). Подобные эффекты наблюдались ранее при отжиге слоистых структур $\mathrm{GeO} / \mathrm{SiO}_{2}$ [19], однако в нашем случае пленки являлись изначально твердыми растворами, и эффекты самоорганизации, приведшие к возникновению слоистых структур, требуют дополнительного изучения. Наблюдается также диффузия германия к поверхности кремния, поэтому мы исследовали эту область пленки с большим разрешением (рис. 3,d). Более светлая область это естественный окисел кремния, а вблизи него наблюдается слой НК размерами 6-7 $\mathrm{nm}$.

На рис. 4, $a, b$ показаны спектры ФЛ-пленок в ИК-диапазоне. Для удобства восприятия спектры приведены в логарифмическом масштабе по вертикальной оси. В исходных пленках при низких температурах обнаружена широкая полоса ФЛ с максимумом $1050 \mathrm{~nm}$. ФЛ, вероятно, обусловленная дефектами, предположительно вакансиями кислорода и избыточными атомами германия. В спектрах видны узкие линии: это паразитная линия лазера $(1080 \mathrm{~nm})$ а также сигнал от подложки кремния, так как излучение лазера достигает подложки. Самая интенсивная из них это линия на длине волны $1132 \mathrm{~nm}$ (линия излучения с участием ТО-фонона в кремнии $\mathrm{Si}-\mathrm{TO})$. Отжиг при $550^{\circ} \mathrm{C}$ привел к возникновению широкого пика ФЛ с максимумом примерно 1300-1450 nm (кривые 2 на рис. $4, a, b)$. Для обоих образцов эта полоса предположительно связана с оптическими переходами в нанокластерах аморфного германия. Обычно, оптическая щель в аморфных материалах больше чем в кристаллических, а длинноволновое „плечо“ может быть обусловлено хвостами Урбаха в плотности состояний аморфных материалов. После отжига $650^{\circ} \mathrm{C}$ в пленках 
$a$

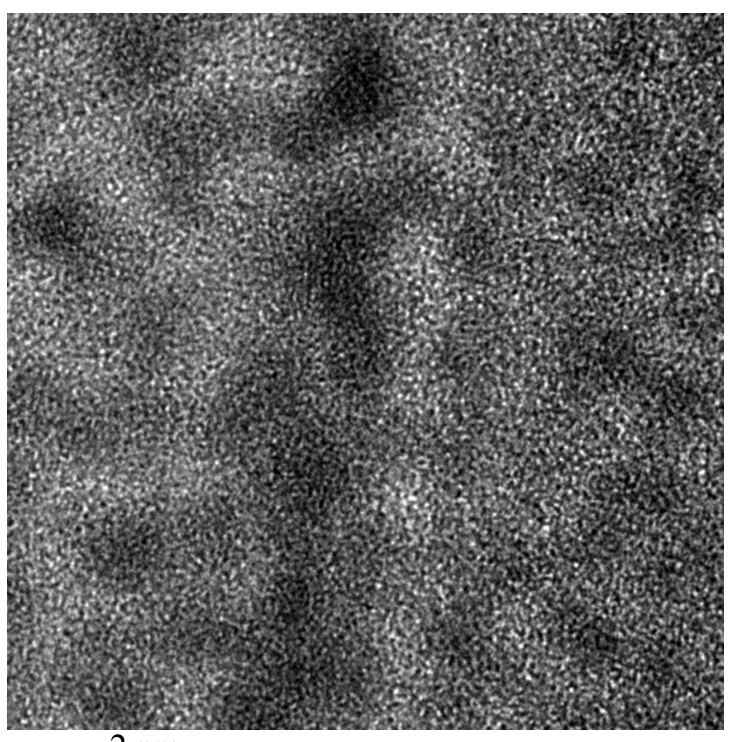

$-2 \mathrm{~nm}$

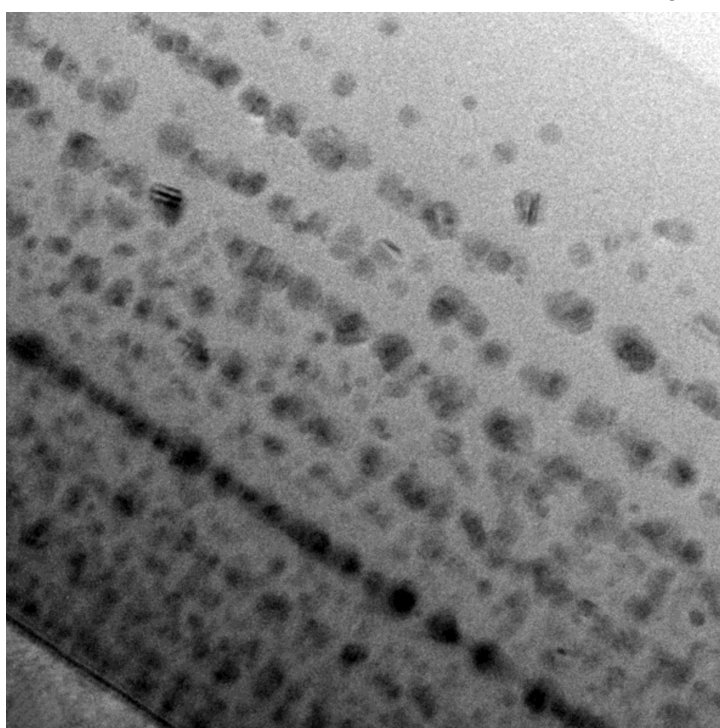

$20 \mathrm{~nm}$

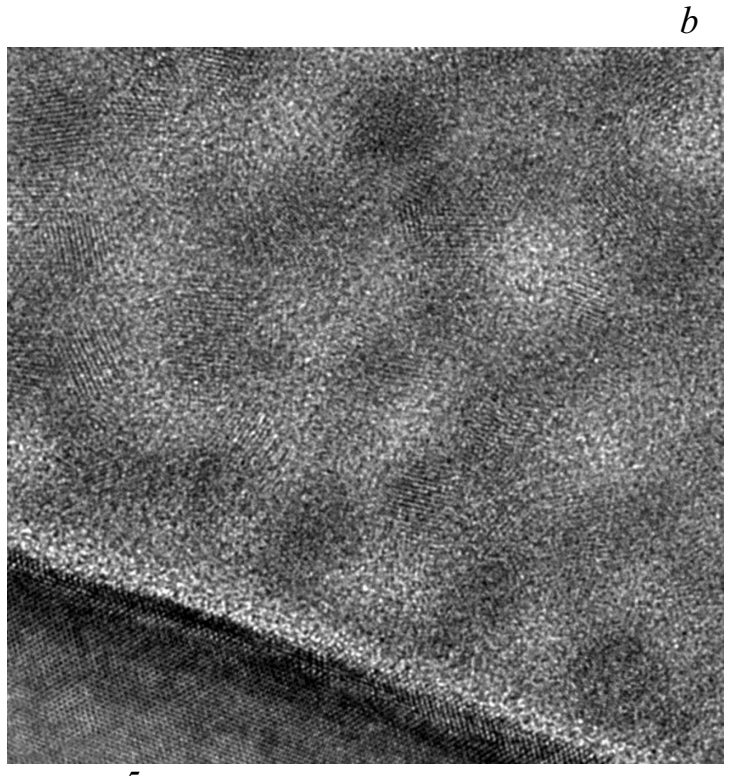

$5 \mathrm{~nm}$

$d$

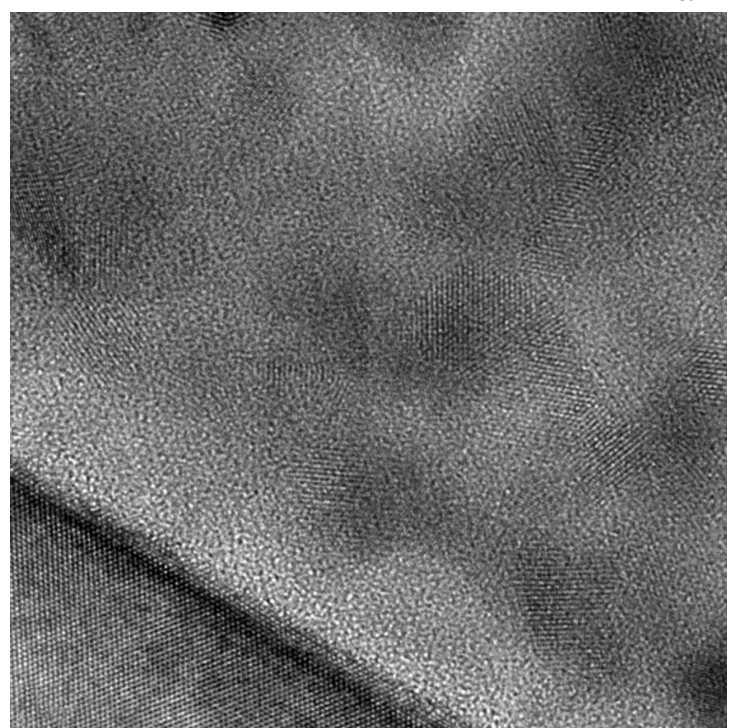

$5 \mathrm{~nm}$

Рис. 3. Изображения ПВРЭМ поперечного среза образцов: $a-\mathrm{GeO}[\mathrm{SiO}]$ исходный; $b-\mathrm{GeO}[\mathrm{SiO}]$ после отжига $650^{\circ} \mathrm{C}$; $c-\mathrm{GeO}\left[\mathrm{SiO}_{2}\right]$ после отжига $650^{\circ} \mathrm{C} ; d-\mathrm{GeO}\left[\mathrm{SiO}_{2}\right]$ после отжига $650^{\circ} \mathrm{C}$, область $\mathrm{Si}-$ интерфейса, большее увеличение.

возникают НК $\mathrm{Ge}$, однако интенсивность ФЛ уменьшается (кривые 3 на рис. $4 a, b)$. Длинноволновая ФЛ (часть которой обрезана вследствие края чувствительности детектора) по-видимому, обусловлена вкладом $\mathrm{HK} \mathrm{Ge}$ с различными размерами. Квантово-размерный эффект приводит к увеличению энергии оптических переходов для экситонов в $\mathrm{HK} \mathrm{Ge}$. В спектре образца $\mathrm{GeO} / \mathrm{SiO}_{2}$ после отжига $650^{\circ} \mathrm{C}$ (кривая 3 на рис. $4, a$ ) проявляется рост сигнала при увеличении длины волны от $1600 \mathrm{~nm}$, однако он обрезается детектором (показано стрелкой). Итак, отжиги вызывают трансформацию структуры пленок и меняют вид спектров ФЛ. В пленках, содержащих $\mathrm{HK} \mathrm{Ge}$, наблюдается длинноволновая ФЛ. При этом уменьшился сигнал ФЛ от дефектов. Была исследована температурная зависимость интенсивности пиков ФЛ (данные не показаны), интенсивность ФЛ падала с ростом температуры, но сигнал обнаруживался при температурах до $200 \mathrm{~K}$.

На рис. 5, $a, b$ приведены спектры ФЛ при комнатной температуре $\left(T_{R T}\right)$ в видимом диапазоне. Наблюдаемая полоса с максимумом $\sim 400 \mathrm{~nm}$ обусловлена комплексами дефектов - вакансия кислорода + избыточные атомы германия (два соседних атома Ge в матрице $\left.\mathrm{SiO}_{2}\right)$ [20,36,37]. Менее интенсивная полоса ФЛ имеет максимум $\sim 570^{\circ} \mathrm{nm}$. Можно предположить, что эта полоса также обусловлена дефектами [32], связанными c Ge, эти сложные дефекты, очевидно, содержат более двух соседних атомов Ge в матрице германосиликатного 

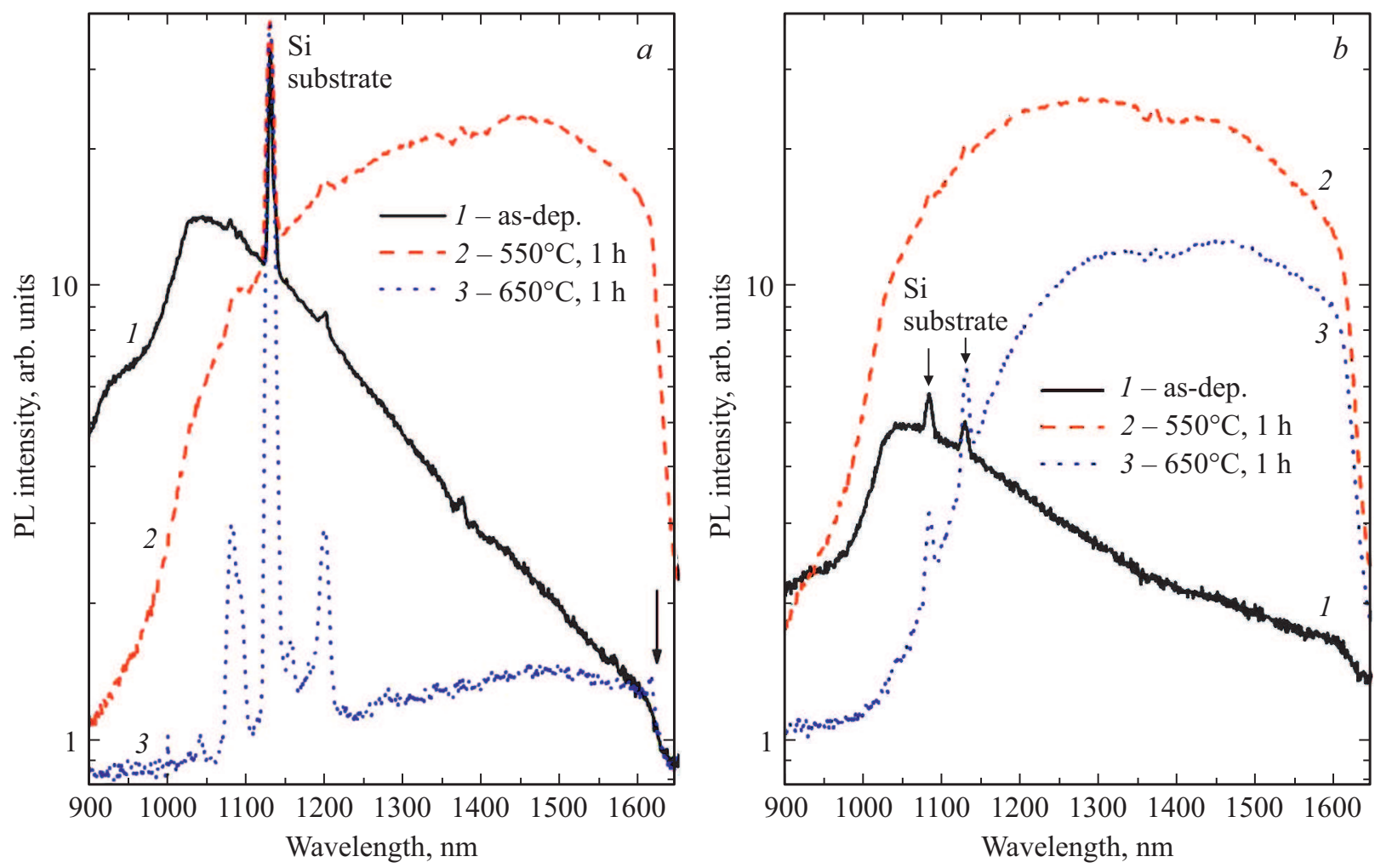

Рис. 4. Спектры фотолюминесценции при низкой температуре в ИК-диапазоне исходных образцов и после отжигов 550 и $650^{\circ} \mathrm{C}$ : $a-\mathrm{GeO}\left[\mathrm{SiO}_{2}\right] ; b-\mathrm{GeO}[\mathrm{SiO}] .\left(T=8 \mathrm{~K}, \lambda_{\mathrm{exc}}=325 \mathrm{~nm}\right)$.
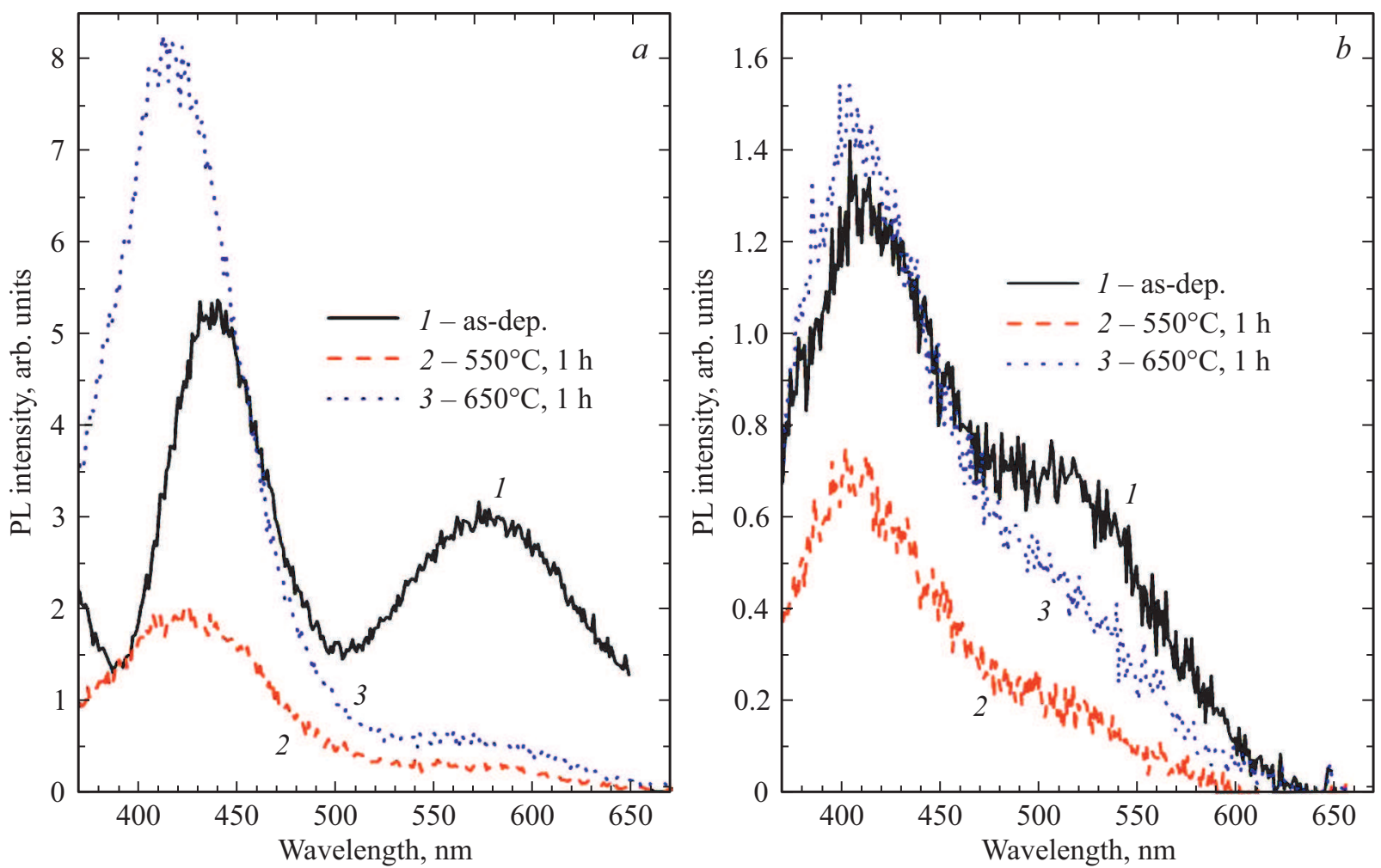

Рис. 5. Спектры фотолюминесценции при комнатной температуре в видимом диапазоне исходных образцов и после отжигов 550 и $650^{\circ} \mathrm{C}: a-\mathrm{GeO}\left[\mathrm{SiO}_{2}\right] ; b-\mathrm{GeO}[\mathrm{SiO}] .\left(T=T_{R T}, \lambda_{\text {exc }}=325 \mathrm{~nm}\right)$. 
стекла. Отметим, что интенсивность ФЛ ведет себя немонотонно с температурой отжига: сначала она падает после отжига $550^{\circ} \mathrm{C}$, и потом растет после отжига $650^{\circ} \mathrm{C}$. Вероятно это связано с отжигом не только светоизлучающих дефектов (что приводит к падению ФЛ), но и с отжигом нерадиационных дефектов (это повышает вероятность излучательных переходов). Итого, можно утверждать что, полосы ФЛ в видимом диапазоне связаны с комплексами дефектов, включающих кислородные вакансии.

\section{4. Выводы}

Обнаружено, что в пленках, полученных сораспылением оксида германия и монооксида кремния на холодную подложку $\left(100^{\circ} \mathrm{C}\right)$ присутствуют нанокластеры аморфного германия со средними размерами $\sim 3 \mathrm{~nm}$. Отжиги при температуре $550^{\circ} \mathrm{C}$ приводят к увеличению доли аморфного германия в данной пленке и к возникновению нанокластеров Ge в пленке, полученной сораспылением оксида германия и диоксида кремния. Отжиги при температуре $650^{\circ} \mathrm{C}$ приводят к возникновению нанокристаллов германия, причем в пленке $\mathrm{GeO}[\mathrm{SiO}]$ их размер меньше, а содержание аморфной фазы больше чем в пленке $\mathrm{GeO}\left[\mathrm{SiO}_{2}\right]$. В обоих типах исходных пленок обнаружена фотолюминесценция при низкой температуре в ИК-диапазоне, предположительно от дефектов. После отжигов максимум фотолюминесценции сместился в длинноволновую область (1500-1600 нм), данный пик предположительно обусловлен оптическими переходами в кластерах германия. К сожалению, мы не обнаружили четких свидетельств проявления квантоворазмерного эффекта в спектрах фотолюминесценции от нанокристаллов германия, это будет являться предметом дальнейшего исследования.

\section{Благодарности}

Володин В.А. благодарен администрации Университета Лотарингии за возможность визита.

\section{Финансирование работы}

Работа выполнена при поддержке РФФИ, проект № 19-07-00367.

\section{Конфликт интересов}

Авторы заявляют, что у них нет конфликта интересов.

\section{Список литературы}

[1] Zhenyi Ni, Shu Zhou, Shuangyi Zhao, Wenbing Peng, Deren Yang, Xiaodong Pi. Mater. Sci. Eng. R 138, 85 (2019).

[2] E.G. Barbagiovanni, D.J. Lockwood, P.J. Simpson, L.V. Goncharova. Appl. Phys. Rev. 1, 011302 (2014).
[3] C. Sun, M.T. Wade, Y. Lee, J.S. Orcutt, L. Alloattiet, M.S. Georgas, A.S. Waterman, J.M. Shainline, R.R. Avizienis, Sen Lin, B.R. Moss, R. Kumar, F. Pavanello, A.H. Atabaki, H.M. Cook, A.J. Ou, J.C. Leu, Yu-Hsin Chen, Krste Asanović, Rajeev J. Ram, Miloš A. Popović, V.M. Stojanović. Nature 528, 534 (2015).

[4] Y. Maeda, N. Tsukamoto, Y. Yazawa, Y. Kanemitsu, Y. Masumoto. Appl. Phys. Lett. 59, 3168 (1991).

[5] L. Pavesi, L.D. Negro, C. Mazzoleni, G. Franz, F. Priolo. Nature 408, 440 (2000).

[6] В.А. Володин, Е.Б. Горохов, М.Д. Ефремов, Д.В. Марин, Д.А. Орехов. Письма в ЖЭТФ 77, 485 (2003).

[7] Е.Б. Горохов, В.А. Володин, Д.В. Марин, Д.А. Орехов, А.Г. Черков, А.К. Гутаковский, В.А. Швец, А.Г. Борисов, Е.Д. Ефремов. ФТП 39, 1210 (2005).

[8] X. Wang, L.C. Kimerling, J. Michel, J. Liu. Appl. Phys. Lett. 102, 131116 (2013).

[9] В.А. Володин, Л.В. Соколов. Письма в ЖЭТФ 101, 455 (2015).

[10] В.А. Володин, В.А. Тимофеев, А.Р. Туктамышев, А.И. Никифоров. Письма в ЖЭТФ 105, 305 (2017).

[11] V. Kveder, M. Badylevich, E. Steinman, A. Izotov, M. Seibt, W. Schröter. Appl. Phys. Lett. 84, 2106 (2004).

[12] M. Ardyanian, H. Rinnert, M. Vergnat. J. Luminescence 129, 729 (2009).

[13] S.G. Cherkova, V.A. Volodin, V.A. Skuratov, M. Stoffel, H. Rinnert, M. Vergnat. J. Luminescence 207, 209 (2019).

[14] S. Takeoka, K. Toshikiyo, M. Fujii, Shinji Hayashi, Keiichi Yamamoto. Phys. Rev. B 61, 15988 (2000).

[15] A. Nyrow, C. Sternemann, C.J. Sahle, A. Hohl, M. Zschintzsch-Diaset. Nanotechnology 24, 165701 (2013).

[16] X.D. Pi, U. Kortshagen. Nanotechnology 20, 295602 (2009).

[17] V.A. Volodin, D.V. Marin, H. Rinnert, M. Vergnat. J. Phys. D: Appl. Phys. 46, 275305 (2013).

[18] В.А. Володин, М.П. Гамбарян, А.Г. Черков, В.И. Вдовин, M. Stoffel, H. Rinnert, M. Vergnat. ЖЭТФ 148, 1225 (2015).

[19] V.A. Volodin, M.P. Gambaryan, A.G. Cherkov, M. Stoffel, H. Rinnert, M. Vergnat. Mater. Res. Express 3, 085019 (2016).

[20] V.A. Volodin, A.G. Cherkov, A.Kh. Antonenko, M. Stoffel, H. Rinnert, M. Vergnat. Mater. Res. Express 4, 075010 (2017).

[21] M. Ardyanian, H. Rinnert, M. Vergnat. J. Appl. Phys. 100, 113106 (2006).

[22] M. Ardyanian, H. Rinnert, X. Devaux, M. Vergnat. Appl. Phys. Lett. 89, 011902 (2006).

[23] Д.В. Марин, В.А. Володин, Е.Б. Горохов, Д.В. Щеглов, A.В. Латышев, M. Vergnat, J. Koch, B.N. Chichkov. Письма в ЖТФ 36, 102 (2010).

[24] D.V. Marin, V.A. Volodin, H. Rinnert, M. Vergnat. Письма в ЖЭТФ 95, 472 (2012).

[25] A.V. Kolobov. J. Appl. Phys. 87, 2926 (2000).

[26] W. Wihl, M. Cardona, J. Tauc. J. Non-Crystalline Solids 8-10, 172 (1972).

[27] V.A. Volodin, G.N. Kamaev, V.A. Gritsenko, A.A. Gismatulin, A. Chin, M. Vergnat. Appl. Phys. Lett. 114, 233104(1-5) (2019).

[28] J.H. Parker, Jr., D.W. Feldman, M. Ashkin. Phys. Rev. 155, 712 (1967).

[29] V.A. Volodin, D.V. Marin, V.A. Sachkov, E.B. Gorokhov, H. Rinnert, M. Vergnat. ЖЭТФ 145, 77 (2014). 
[30] C.T. Kirk. Phys. Rev. B 38, 1255 (1988).

[31] P.G. Pai, S.S. Chao, Y. Takagi, G. Lucovsky. J. Vacuum Sci. Technology A 4, 689 (1986).

[32] В.A. Володин, Zhang Rui, Г.К. Кривякин, А.X. Антоненко, M. Stoffel, H. Rinnert, M. Vergnat. ФТП 52, 1056 (2018).

[33] M. Seck, R.A.B. Devine, C. Hernandez, Y. Campidelli, J.-C. Dupuy. Appl. Phys. Lett. 72, 2748 (1998).

[34] A.L. Shabalov, M.S. Feldman. Phys. Status Solidi A 83, K11 (1984).

[35] D.A. Jishiashvili, E.R. Kutelia. Phys. Status Solidi B 143, K147 (1987).

[36] L. Rebohle, J. von Borany, R.A. Yankov, W. Skorupa, I.E. Tyschenko, H. Fröb, K. Leo. Appl. Phys. Lett. 71, 2809 (1997).

[37] W. Skorupa, L. Rebohle, T. Gebel. Appl. Phys. A 76, 1049 (2003).

Редактор Ю.Э. Китаев 